\title{
UTILIZAÇÃO DE CONCHAS DE SURURU COMO FONTE ALTERNATIVA DE CÁLCIO PARA CODORNAS JAPONESAS
}

\author{
Sandra Roseli Valerio Lana ${ }^{*}$, Geraldo Roberto Quintão Lana ${ }^{1}$, Romilton Ferreira Barros Júnior ${ }^{1}$, Maria \\ Pollyane Lima Silva1, Daniel Silva Santos ${ }^{1}$, Ana Patrícia Alves Leão²
}

\author{
1 Universidade Federal de Alagoas, Campus de Engenharias e de Ciências Agrárias, Rio Largo, Alagoas \\ ${ }^{2}$ Universidade Federal de Lavras, Departamento de Zootecnia, Lavras, Minas Gerais \\ *Autor para correspondência: Sandra Roseli Valerio Lana, sandraroselilana@gmail.com
}

\begin{abstract}
RESUMO: Objetivou-se avaliar a influência da utilização de conchas de sururu (CS) na alimentação de codornas japonesas sobre o desempenho produtivo e viabilidade econômica durante o período de um a 35 dias de idade. Foram utilizadas 360 codornas japonesas alojadas em gaiolas do tipo bateria de arame galvanizado. 0 delineamento experimental utilizado foi o inteiramente casualizado, com seis tratamentos e seis repetições, com 10 aves por unidade experimental. Os tratamentos foram: T1 - Ração basal com 0,90\% de cálcio, oriundo do calcário calcítico; T2 - Ração basal com redução de $20 \%$ de cálcio oriundo da CS fornecendo $0,72 \%$ de cálcio; T3 - Ração basal com redução de $10 \%$ de cálcio oriundo da CS fornecendo 0,81\% de cálcio; T4 - Ração basal com aumento de $10 \%$ de cálcio oriundo da CS fornecendo 0,99\% de cálcio; T5 - Ração basal com aumento de $20 \%$ de cálcio oriundo da CS fornecendo 1,08\% de cálcio e T6 - Ração basal contendo 0,90\% de cálcio oriundo da CS. As variáveis de desempenho avaliadas foram: ganho de peso, consumo de ração e conversão alimentar. Houve diferença significativa $(p<0,05)$ para consumo de ração das codornas no período de um a 35 dias de idade, sendo o T3 (0,81\% de cálcio oriundo CS) apresentando o melhor resultado, bem como para viabilidade econômica. A farinha de conchas de sururu pode ser utilizada em até $100 \%$ de substituição ao calcário calcítico nas rações de codornas japonesas de um a 35 dias de idade, sem afetar o desempenho das aves, além disso, permite reduzir 0 nível de cálcio das rações para 0,81\%.
\end{abstract}

PALAVRAS CHAVE: Coturnix japonica, desempenho, postura, subproduto do sururu

\section{SURURU SHELL UTILIZATION AS ALTERNATIVE SOURCE OF CALCIUM FOR JAPANESE QUAILS}

\begin{abstract}
The objective of this study was to evaluate the influence of the use of sururu shells (CS) on the feeding of Japanese quails on the productive performance and economic viability during the period from one to 35 days of age. We used 360 Japanese quails housed in battery-type galvanized wire cages. The experimental design was completely randomized, with six treatments and six replications, with 10 birds per experimental unit. The treatments were: T1 - Basal diet with $0.90 \%$ calcium, derived from calcitic limestone; T2 - Basal diet with $20 \%$ reduction of calcium from CS providing $0.72 \%$ of calcium; T3 - Basal diet with $10 \%$ reduction of calcium from CS providing $0.81 \%$ of calcium; T4 - Basal diet with 10\% calcium increase from CS providing $0.99 \%$ calcium; T5 - Basal diet with $20 \%$ increase in calcium from CS providing $1.08 \%$ of calcium and T6 - Basal diet containing $0.90 \%$ of calcium from CS. The performance variables evaluated were: weight gain, feed intake and feed conversion. There was a significant difference $(p<0.05)$ for quail feed intake from one to 35 days of age, with T3 $(0.81 \%$ of calcium from CS) showing the best result, as well as economic viability. Sururu shell flour can be used up to $100 \%$ as a substitute for calcitic limestone in Japanese quail feed from one to 35 days of age, without affecting the performance of poultry $0.81 \%$.
\end{abstract}

KEY WORDS: Coturnix japonica, performance, posture, sururu byproduct

\section{INTRODUÇÃO}

A coturnicultura vem se consolidando como uma ótima alternativa de agronegócio no Brasil, apresentando desenvolvimento bastante acentuado nos últimos anos. Este cenário se deve à alta postura de ovos, rápido retorno financeiro, alta produtividade e elevado valor nutricional do ovo, que tem levado a um número cada vez maior de adeptos a sua criação 
(Pastore et al., 2012; Ludke et al., 2018; Bittencourt et al., 2019).

Os alimentos de origem vegetal, normalmente milho e farelo de soja, constituem a base da alimentação das aves e possuem teores de cálcio em níveis insuficientes para suprir as exigências nutricionais. Desta forma, há necessidade de fazer uma suplementação de cálcio na dieta para atender estas exigências dos animais (Sá et al., 2004). 0 cálcio requer uma atenção especial, pois, está diretamente relacionado com a qualidade das cascas dos ovos e do tecido muscular. Um consumo inadequado de cálcio pode acarretar problemas na conformação óssea, queda na postura e má qualidade das cascas dos ovos com um elevado índice de quebra.

Pode-se destacar o grande interesse das pesquisas, na substituição de fontes inorgânicas de cálcio por fontes orgânicas, uma vez que a extração do calcário calcítico proveniente das rochas, gera um impacto ambiental que pode ser prejudicial ao longo dos anos (Araújo et al., 2008; Costa et al., 2010). Deste modo, surge as conchas de sururu como fonte alternativa de cálcio orgânico nas rações de codornas de postura, haja vista, seu elevado teor em cálcio, onde além de ser um recurso renovável, apresenta como vantagens a grande disponibilidade do molusco na natureza, principalmente no litoral do Nordeste, especificamente no estado de Alagoas.

O sururu (Mytella falcata) é um molusco nativo do complexo estuarino lagunar mundaú-manguaba (Maceió - AL), muito apreciado na culinária alagoana, e importante para a geração de renda e subsistência. Como principal recurso pesqueiro das lagunas, 0 descarte inadequado do coproduto do processamento polui o entorno das áreas de pesca e pode representar uma grande fonte de contaminação (Silva et al., 2013).

Porém, é necessária a realização de pesquisas que possam dar mais precisão sobre a quantidade exata desses minerais que estão presentes nas conchas a serem utilizadas para a produção de ração. Nesse enfoque, é constante a busca de fontes suplementares menos onerosas para a formulação de rações para animais.
Diante deste contexto, o presente trabalho teve como objetivo avaliar a influência da inclusão das conchas de sururu na alimentação de codornas japonesas sobre 0 desempenho produtivo e viabilidade econômica durante o período de um a 35 dias de idade.

\section{MATERIAL E MÉTODOS}

Todos os procedimentos foram aprovados pelo Comitê de Ética no uso de animais, da Universidade Federal de Alagoas, sob protocolo de $n^{0}$ 20/2014. O presente trabalho foi realizado com apoio da Coordenação de Aperfeiçoamento de Pessoal de Nível Superior - Brasil (CAPES) - Código de Financiamento 001

0 experimento foi realizado no setor de coturnicultura no Centro de Ciências Agrárias da Universidade Federal de Alagoas - UFAL, localizado no município de Rio Largo - AL. Foram utilizadas 360 codornas japonesas, fêmeas com um dia de idade, sendo selecionadas de acordo com o peso médio inicial de 7,8g e distribuídas em um delineamento experimental inteiramente casualizado com seis tratamentos, seis repetições e 10 aves em cada unidade experimental.

Foram utilizadas gaiolas do tipo bateria, de arame galvanizado, com $50 \mathrm{~cm}$ de comprimento, 60 $\mathrm{cm}$ de largura e $30 \mathrm{~cm}$ de altura, com comedouros tipo calha, bebedouro tipo nipple e bandejas coletoras de excretas. As gaiolas foram instaladas em um galpão de alvenaria fechado, com piso de cerâmica, coberta com laje e telhas de cimento amianto, janela $(1,20 \times 1,00 \mathrm{~m})$, ar condicionado de 21000 BTUs e um exaustor.

0 monitoramento das variáveis climáticas foi realizado diariamente, às 8:00 e às 16:00 horas, por meio de termômetros de máxima e de mínima, termohigrômetro e termômetro de globo negro conforme dados da Tabela 1.0 índice de temperatura de globo negro e umidade (ITGU) foi calculado de acordo com a fórmula proposta por Buffington et al. (1981): ITGU $=0,72(\operatorname{Tgn}+$ Tbu $)+40,6$, em que: Tgn - temperatura do globo negro, em ${ }^{\circ} \mathrm{C}$, e Tbu - temperatura de bulbo úmido, $\mathrm{em}^{\circ} \mathrm{C}$.

Tabela 1. Valores médios de temperaturas, umidade relativa do ar e índice de temperatura de globo negro e umidade (ITGU) registradas durante o período experimental

\begin{tabular}{ccccc}
\hline Períodos (dias) & Temperatura Máxima $\left({ }^{\circ} \mathrm{C}\right)$ & Temperatura Mínima $\left({ }^{\circ} \mathrm{C}\right)$ & Umidade Relativa $(\%)$ & ITGU \\
\hline 1 a 14 & 32,2 & 29,30 & 77,20 & 80,70 \\
15 a 21 & 31,3 & 26,50 & 69,40 & 77,80 \\
22 a 35 & 29,9 & 25,50 & 78,10 & 78,00 \\
\hline
\end{tabular}


As rações experimentais foram a base de milho e farelo de soja, seguindo as recomendações preconizadas por Rostagno et al. (2011). Os tratamentos (Tabela 2) foram constituídos por: T1 - Ração basal contendo 0,90\% de cálcio, oriundo do calcário calcítico; T2 - Ração basal com redução de $20 \%$ de cálcio oriundo da farinha da conchas de sururu fornecendo 0,72\% de cálcio; T3 - Ração basal com redução de
$10 \%$ de cálcio oriundo da farinha da conchas de sururu fornecendo 0,81\% de cálcio; T4 - Ração basal com aumento de $10 \%$ de cálcio oriundo da farinha da conchas de sururu fornecendo $0,99 \%$ de cálcio; T5 Ração basal com aumento de $20 \%$ de cálcio oriundo da farinha da conchas de sururu fornecendo 1,08\% de cálcio; T6 - Ração basal contendo 0,90\% de cálcio oriundo da farinha da conchas de sururu.

Tabela 2. Composição percentual das rações experimentais no período de um a 35 dias

\begin{tabular}{|c|c|c|c|c|c|c|}
\hline \multirow[b]{2}{*}{ Ingredientes } & \multicolumn{5}{|c|}{ Tratamentos } & \multirow[b]{2}{*}{ T6 } \\
\hline & T1 & $\mathrm{T} 2$ & T3 & T4 & T5 & \\
\hline Milho & 57,37 & 55,79 & 55,79 & 55,79 & 55,79 & 55,79 \\
\hline Farelo de Soja & 38,31 & 38,59 & 38,59 & 38,59 & 38,59 & 38,59 \\
\hline Fosfato Bicálcico ${ }^{1}$ & 1,38 & 1,38 & 1,38 & 1,38 & 1,38 & 1,38 \\
\hline Calcário calcítico & 1,16 & 0,00 & 0,00 & 0,00 & 0,00 & 0,00 \\
\hline Farinha de conchas de sururu & 0,00 & 0,64 & 0,86 & 1,29 & 1,51 & 1,07 \\
\hline Óleo de Soja & 0,98 & 1,51 & 1,51 & 1,51 & 1,51 & 1,51 \\
\hline Sal comum & 0,39 & 0,39 & 0,39 & 0,39 & 0,39 & 0,39 \\
\hline Suplemento Mineral ${ }^{2}$ & 0,05 & 0,05 & 0,05 & 0,05 & 0,05 & 0,05 \\
\hline Suplemento Vitamínico ${ }^{3}$ & 0,10 & 0,10 & 0,10 & 0,10 & 0,10 & 0,10 \\
\hline DL-Metionina & 0,16 & 0,16 & 0,16 & 0,16 & 0,16 & 0,16 \\
\hline L-Treonina & 0,03 & 0,03 & 0,03 & 0,03 & 0,03 & 0,03 \\
\hline L-Lisina & 0,03 & 0,02 & 0,02 & 0,02 & 0,02 & 0,02 \\
\hline Inerte & 0,00 & 1,28 & 1,06 & 0,63 & 0,41 & 0,85 \\
\hline \multirow[t]{2}{*}{ Total/kg } & 100 & 100 & 100 & 100 & 100 & 100 \\
\hline & \multicolumn{5}{|c|}{ Composição Calculada } & \\
\hline Energia Metabolizável (Kcal/kg) & 2.900 & 2.900 & 2.900 & 2.900 & 2.900 & 2.900 \\
\hline Proteína Bruta (\%) & 22,00 & 22,00 & 22,00 & 22,00 & 22,00 & 22,00 \\
\hline Cálcio (\%) & 0,90 & 0,72 & 0,81 & 0,99 & 1,08 & 0,90 \\
\hline Fósforo Disponível (\%) & 0,37 & 0,37 & 0,37 & 0,37 & 0,37 & 0,37 \\
\hline Sódio (\%) & 0,17 & 0,17 & 0,17 & 0,17 & 0,17 & 0,17 \\
\hline Lisina Dig. (\%) & 1,12 & 1,12 & 1,12 & 1,12 & 1,12 & 1,12 \\
\hline Met + Cist Dig. (\%) & 0,76 & 0,76 & 0,76 & 0,76 & 0,76 & 0,76 \\
\hline Metionina Dig. (\%) & 0,45 & 0,45 & 0,45 & 0,45 & 0,45 & 0,45 \\
\hline Treonina Dig. (\%) & 0,79 & 0,79 & 0,79 & 0,79 & 0,79 & 0,79 \\
\hline Triptofano Dig. (\%) & 0,25 & 0,25 & 0,25 & 0,25 & 0,25 & 0,25 \\
\hline
\end{tabular}

${ }^{1}$ Os níveis de fosfato bicálcico foram fixos. 2Premix Mineral/kg: Mg 150.000 ppm; Zn 140.000 ppm; Fe 100.000 ppm; Cu 16.00 ppm; Selênio 600 ppm; I 1.500 ppm. .Premix Vitamínico/kg: Vit.A 13.440,000 Ul; Vit. D 3.200,000 UI Vit.E 28.000 mg/kg; Vit.K 2.880 mg/kg; Tiamina $3.500 \mathrm{mg} / \mathrm{kg}$; Riboflavina $9.600 \mathrm{mg} / \mathrm{kg}$; Piridoxina $5.000 \mathrm{mg} / \mathrm{kg}$; Cianocobalamina $19.200 \mathrm{mcg} / \mathrm{kg}$; Ácido Fólico $1.600 \mathrm{mg} / \mathrm{kg}$; Ácido Pantotênico 25,000 mg/kg; Niacina 67.200 mg/kg; Biotina 80.000 mcg/kg; Antioxidante 0,40 g/kg.

Para a obtenção das conchas de sururu foi realizada uma coleta do subproduto, às margens da lagoa Mundaú em Maceió - AL, em seguida foram lavadas, trituradas e colocadas em estufa de 180 a $240^{\circ} \mathrm{C}$ por 20 a 30 minutos, para posteriormente proceder-se a moagem. A farinha das conchas de sururu utilizada nesse experimento continha $38 \%$ de cálcio.
O fornecimento de água e ração foi à vontade durante todo período experimental. As variáveis avaliadas foram: consumo de ração, ganho de peso e conversão alimentar. Para os cálculos do desempenho produtivo, as aves e as sobras de ração foram pesadas semanalmente.

A análise econômica foi feita de acordo com metodologia descrita por Lana (2000), em função das 
variações no peso vivo, consumo de ração e custos das rações, que ocorreram entre os tratamentos utilizados. Assim, a análise econômica é inerente ao componente de produção e alimentação, haja vista que a mão de obra e outros gastos com a criação das aves foram iguais para todos os tratamentos. 0 preço de venda da codorna e os valores das matérias-primas, utilizados para o cálculo dos custos das rações, referem-se aos valores praticados na região no período da realização do experimento.

As análises estatísticas das variáveis estudadas foram realizadas utilizando o programa SAEG (UFV,
2007) e as médias obtidas foram submetidas ao teste de Dunnett ao nível de $5 \%$ de probabilidade.

\section{RESULTADOS E DISCUSSÃO}

Os resultados referentes ao consumo de ração (CR), ganho de peso (GP) e conversão alimentar (CA) de codornas japonesas nas fases de um a sete; oito a $14 ; 15$ a 21; 22 a 28 e 29 a 35 dias de idade, alimentadas com rações contendo a inclusão da farinha das conchas de sururu como fonte alternativa de cálcio, são apresentados na Tabela 3.

Tabela 3. Consumo de ração (CR) (g), ganho de peso (GP) (g) e conversão alimentar (CA), diferentes fases (dias), de codornas alimentadas com rações contendo a inclusão de farinha de conchas de sururu.

\begin{tabular}{|c|c|c|c|c|c|c|c|c|}
\hline \multirow[b]{2}{*}{ Fases } & \multicolumn{7}{|c|}{ Tratamentos $^{1}$} & \multirow[b]{2}{*}{ CV $(\%)$} \\
\hline & Variáveis & $\mathrm{T} 1$ & $\mathrm{~T} 2$ & T3 & T4 & T5 & T6 & \\
\hline \multirow{3}{*}{$1-7$} & $\mathrm{CR}$ & 40,29 & 39,63 & 40,14 & 38,04 & 36,91 & 38,63 & 12,32 \\
\hline & GP & 22,69 & 23,42 & 23,29 & 22,41 & 21,62 & 22,04 & 6,06 \\
\hline & $\mathrm{CA}$ & 1,77 & 1,69 & 1,72 & 1,69 & 1,67 & 1,75 & 10,17 \\
\hline \multirow{3}{*}{$8-14$} & $\mathrm{CR}$ & 68,04 & 68,20 & 73,92 & 68,30 & 78,08 & 73,08 & 22,26 \\
\hline & GP & 30,97 & 31,92 & 31,46 & 33,21 & 34,97 & 31,35 & 5,20 \\
\hline & $\mathrm{CA}$ & 2,19 & 2,14 & 2,35 & 2,05 & 2,24 & 2,33 & 21,79 \\
\hline \multirow{3}{*}{$15-21$} & CR & 99,21 & 100,10 & 98,86 & 101,15 & 99,40 & 99,27 & 4,62 \\
\hline & $\mathrm{GP}^{*}$ & $37,72 \mathrm{a}$ & $39,56 \mathrm{a}$ & $37,32 \mathrm{a}$ & $40,12 b$ & $39,13 a$ & $36,54 a$ & 4,73 \\
\hline & $\mathrm{CA}$ & 2,63 & 2,52 & 2,64 & 2,52 & 2,54 & 2,72 & 4,61 \\
\hline \multirow{3}{*}{$22-28$} & $\mathrm{CR}$ & 63,02 & 63,38 & 71,35 & 69,10 & 62,18 & 62,26 & 12,14 \\
\hline & GP & 32,48 & 33,94 & 33,67 & 33,99 & 31,10 & 30,60 & 10,88 \\
\hline & $\mathrm{CA}$ & 1,96 & 1,88 & 2,12 & 1,88 & 2,05 & 2,13 & 21,24 \\
\hline \multirow{3}{*}{$29-35$} & $\mathrm{CR}$ & 154,76 & 149,01 & 106,30 & 149,63 & 158,21 & 148,71 & 7,22 \\
\hline & $\mathrm{GP}^{*}$ & 31,81 a & $24,10 b$ & $32,49 a$ & $21,03 b$ & $27,20 \mathrm{~b}$ & $24,65 b$ & 17,37 \\
\hline & $C A^{*}$ & $4,91 \mathrm{~b}$ & $6,24 \mathrm{a}$ & $3,27 \mathrm{~b}$ & $7,34 a$ & $5,81 \mathrm{a}$ & $6,55 \mathrm{a}$ & 18,42 \\
\hline
\end{tabular}

${ }^{1} \mathrm{~T} 1-0,90 \%$ de cálcio oriundo do calcário calcítico; T2 - $0,72 \%$ de cálcio oriundo da farinha de conchas de sururu; T3 - 0,81\% de cálcio oriundo da farinha das conchas de sururu; $\mathrm{T} 4-0,99 \%$ de cálcio oriundo da farinha das conchas de sururu; $\mathrm{T} 5-1,08 \%$ de cálcio oriundo da farinha das conchas de sururu e T6-0,90\% de cálcio oriundo da farinha das conchas de sururu.

*Médias seguidas por letras distintas na linha, diferem entre si pelo teste de Dunnett $(p<0,05)$.

Não houve diferença significativa $(p<0,05)$ para consumo de ração, ganho de peso e conversão alimentar de codornas nas fases de um a sete, oito a 14 e 22 a 28 dias de idade. JáAlves et al. (2002), encontrou diferentes resultados, quando avaliaram o efeito de concentrações de cálcio na ração para pintos de corte e observaram redução do consumo e ganho de peso à medida que o nível de cálcio da ração aumentava.

Para a fase de 15 a 21 dias de idade não houve diferença significativa $(p>0,05)$ para consumo de ração e conversão alimentar das aves, no entanto, o ganho de peso foi significativamente $(p<0,05)$ maior para as codornas alimentadas com ração contendo o nível de 0,99\% de Ca oriundo da farinha de conchas de sururu (T4). Por outro lado, Costa et al. (2009), estudando níveis de cálcio para codornas japonesas fêmeas aos 21 dias de idade verificou aumento no consumo de ração e obteve a exigência de 1,26\% de cálcio.

Não houve $(p>0,05)$ diferenças significativas para o consumo de ração das aves entre os tratamentos avaliados no período de 29 a 35 dias de idade. As codornas que receberam a ração contendo $0,81 \%$ de cálcio oriundo da farinha de conchas de sururu (T3) apresentaram maior $(p<0,05)$ ganho de peso e melhor 
conversão alimentar $(3,27)$ em relação aos demais tratamentos avaliados.

$\mathrm{Na}$ Tabela 4 encontram-se os resultados referentes ao consumo de ração $(\mathrm{CR})$, ganho de peso
(GP) e conversão alimentar (CA) de codornas nos períodos de um a 21, 22 a 35 e um a 35 dias de idade utilizando rações contendo farinha de conchas de sururu como fonte de cálcio.

Tabela 4. Consumo de ração (g), ganho de peso ( $\mathrm{g}$ ) e conversão alimentar de codornas japonesas de 1 a 21, 22 a 28 e 29 a 35 dias de idade de codornas alimentadas com rações contendo a inclusão de farinha de conchas de sururu.

\begin{tabular}{ccccccccc}
\hline & \multicolumn{7}{c}{ Tratamentos $^{1}$} \\
\hline Fases (dias) & Varíveis & T1 & T2 & T3 & T4 & T5 & T6 & CV (\%) \\
\hline \multirow{3}{*}{$1-21$} & $\mathrm{CR}$ & 207,55 & 207,94 & 212,93 & 207,50 & 214,40 & 210,99 & 8,53 \\
& $\mathrm{GP}$ & 91,39 & 94,91 & 92,08 & 95,75 & 95,73 & 89,94 & 3,36 \\
& $\mathrm{CA}$ & 2,41 & 2,19 & 2,31 & 2,16 & 2,24 & 2,34 & 8,22 \\
\hline \multirow{3}{*}{$22-35$} & $\mathrm{CR}$ & 220,70 & 212,40 & 177,65 & 218,74 & 220,39 & 210,98 & 5,29 \\
& $\mathrm{GP}^{*}$ & $64,30 \mathrm{a}$ & $58,04 \mathrm{a}$ & $66,16 \mathrm{a}$ & $55,02 \mathrm{~b}$ & $58,31 \mathrm{a}$ & $55,25 \mathrm{~b}$ & 7,72 \\
& $\mathrm{CA}^{*}$ & $3,49 \mathrm{a}$ & $3,66 \mathrm{a}$ & $2,68 \mathrm{~b}$ & $4,01 \mathrm{a}$ & $3,67 \mathrm{a}$ & $3,84 \mathrm{a}$ & 9,63 \\
\hline \multirow{3}{*}{$1-35$} & $\mathrm{CR}$ & $435,50 \mathrm{a}$ & $420,34 \mathrm{a}$ & $390,59 \mathrm{~b}$ & $426,24 \mathrm{a}$ & $434,79 \mathrm{a}$ & $421,97 \mathrm{a}$ & 5,26 \\
& $\mathrm{GP}$ & 152,20 & 152,95 & 158,25 & 150,78 & 154,04 & 145,19 & 3,50 \\
& $\mathrm{CA}$ & 2,86 & 2,75 & 2,46 & 2,83 & 2,77 & 2,91 & 5,88 \\
\hline
\end{tabular}

${ }^{1}$ T1 - 0,90\% de cálcio oriundo do calcário calcítico; T2 - 0,72\% de cálcio oriundo da farinha das conchas de sururu; T3 - 0,81\% de cálcio oriundo da farinha das conchas de sururu; T4 - 0,99\% de cálcio oriundo da farinha das conchas de sururu; T5 - 1,08\% de cálcio oriundo da farinha das conchas de sururu e T6 - 0,90\% de cálcio oriundo da farinha das conchas de sururu.

*Médias seguidas por letras distintas na linha diferem entre si pelo teste de Dunnett $(p<0,05)$;

Na fase de um a 21 dias de idade não houve diferença significativa $(p>0,05)$ entre os tratamentos com substituição do calcário pela farinha de conchas de sururu para nenhuma das variáveis avaliadas. Estes resultados foram semelhantes aos obtidos por Sá et al. (2004) que não constataram efeito dos níveis de cálcio sobre o consumo de ração e conversão alimentar de frangos de corte. No entanto, estudos realizados por Alves et al. (2002) avaliando o efeito de concentrações de cálcio em rações para pintos de corte, demonstraram redução do consumo e ganho de peso. Apesar de não ter ocorrido diferenças significativas a conversão alimentar das codornas que receberam a ração contendo 0,99\% de cálcio oriundo da farinha de conchas de sururu (T4) apresentou melhor índice $(2,16)$ em relação aos demais tratamentos.

O consumo de ração das codornas de 22 a 35 dias de idade não diferiu significativamente $(p>0,05)$ entre os tratamentos avaliados. 0 ganho de peso $(66,16$ g) e a conversão $(2,68)$ das codornas que receberam ração com $0,81 \%$ de cálcio oriundo da farinha de conchas de sururu (T3) diferiram significativamente $(p<0,05)$, comparados aos demais tratamentos avaliados.

Houve diferença significativa $(p<0,05)$ para 0 consumo de ração das codornas na fase de um a 35 dias de idade entre os tratamentos estudados. As aves que consumiram a ração contendo $0,81 \%$ de cálcio oriundo da farinha de conchas de sururu apresentaram menor $(309,59 \mathrm{~g})$ consumo quando comparadas com os demais tratamentos. Resultados semelhantes foram obtidos por Costa et al. (2009), que constataram menor consumo de ração para codornas japonesas em rações contendo $0,87 \%$ de cálcio.

Não houve diferença significativa $(p>0,05)$ para ganho de peso e conversão alimentar das codornas na fase de um a 35 dias de idade. Embora não tenha ocorrido diferenças significativas entre os tratamentos estudados, pode-se constatar que as codornas que ingeriram ração com $0,81 \%$ de cálcio oriundo da farinha de conchas de sururu apresentaram em valores absolutos maior ganho de peso $(158,25 \mathrm{~g})$ e melhor conversão alimentar $(2,46)$.

No que se refere às necessidades de minerais para aves, os macrominerais como cálcio e fósforo aparecem como os mais limitantes. Desta forma, estes devem estar disponíveis na dieta em quantidades e proporções adequadas para atender às necessidades dos animais, considerando a idade, a raça, a categoria ou a situação fisiológica e o sistema de produção adotado (Gomes et al., 2004). 
Os resultados da viabilidade econômica de codornas japonesas de um a 35 dias de idade da inclusão de conchas do sururu na alimentação encontram-se na tabela 5.

Tabela 5. Análise econômica dos diferentes tratamentos aos 35 dias de idade

\begin{tabular}{cccccccc}
\hline Tratamento & $\begin{array}{c}\text { RBM } \\
\text { (R\$/ave) }\end{array}$ & $\begin{array}{c}\text { CMA } \\
\text { (R\$/ave) }\end{array}$ & $\begin{array}{c}\text { MBM } \\
\text { (R\$/ave) }\end{array}$ & $\begin{array}{c}\text { MBR } \\
(\%)\end{array}$ & $\begin{array}{c}\text { RM } \\
(\%)\end{array}$ & $\begin{array}{c}\text { IRR } \\
(\%)\end{array}$ & IBEP \\
\hline T1 & 1,88 & 0,54 & 1,33 & 100,00 & 246,75 & 100,00 & 0,13 \\
T2 & 1,99 & 0,54 & 1,45 & 108,97 & 271,09 & 109,87 & 0,14 \\
T3 & 1,91 & 0,50 & 1,41 & 105,56 & 282,81 & 114,62 & 0,13 \\
T4 & 1,98 & 0,55 & 1,43 & 107,29 & 261,12 & 105,82 & 0,14 \\
T5 & 1,93 & 0,55 & 1,38 & 101,57 & 253,30 & 97,75 & 0,13 \\
T6 & 1,89 & 0,53 & 1,36 & 101,97 & 259,14 & 105,02 & 0,13 \\
\hline
\end{tabular}

${ }^{1} \mathrm{~T} 1$ - 0,90\% de cálcio oriundo do calcário calcítico; T2 - 0,72\% de cálcio oriundo da farinha das conchas de sururu; T3 - 0,81\% de cálcio oriundo da farinha das conchas de sururu; T4 - 0,99\% de cálcio oriundo da farinha das conchas de sururu; T5 - 1,08\% de cálcio oriundo da farinha das conchas de sururu e T6 - 0,90\%de cálcio oriundo da farinha das conchas de sururu.

$\mathrm{RBM}$ = renda bruta média; $\mathrm{CMA}$ = custo médio de arraçoamento; $\mathrm{MBM}=$ margem bruta média; $\mathrm{MBR}$ = margem bruta relativa a ração basal; $R M=$ rentabilidade média; IRR = índice relativo de rentabilidade em relação a ração basal; IBEP = índice bioeconômico ponderado.

Pode-se observar que 0 custo com arraçoamento foi menor para a ração contendo 0,81\% de cálcio oriundo da farinha de conchas de sururu. Verificou-se superioridade para o tratamento contendo $0,81 \%$ de cálcio oriundo da farinha de conchas de sururu (T3) para renda média e índice relativo de rentabilidade em relação aos demais tratamentos avaliados.

Afarinha de conchas de sururu pode ser utilizada como fonte de cálcio em até $100 \%$ de substituição ao calcário calcítico nas rações de codornas japonesas, de um a 35 dias de idade, sem comprometer 0 desempenho das aves, além disso, permite reduzir 0 nível de cálcio das rações para 0,81\%.

\section{REFERÊNCIAS BIBLIOGRÁFICAS}

Alves, E.L; Teixeira, A.S.; Bertechini, A.G; Rodrigues, P.B.; Oliveira, A.I.G. Efeito dos níveis de cálcio em duas fontes sobre o desempenho de frangos de corte. Ciência e agrotecnologia, 2002, 26, 6, 1305-1312.

Araújo, J.A.; Silva, J.H.V.; Amâncio, A.L.L.; Lima, C.B.; Oliveira, E.R.A. Fontes de minerais para poedeiras. Acta Veterinaria Brasilica, 2008, 2, 3, 53-60.

Bittencourt, T.M.; Lima, J.D.; Valentim, J.K; Martins, A.C.S.; Moraleco, D.D.; Vaccaro, B.C. Distillers dried grains with solubles from corn in diet of japanese quails. Acta Scientiarum. Animal Sciences, 2019, 41, 1-7.
Buffington, D.E.; Collazo-Arocho, A.; Canton, G.H.; Pitt, D.; Thatcher, W.; Collier, R.; Black globe-humidity índex (BGHI) as comfort equation for dairy cows. American Society of Agricultural Engineers. 1981, 24, 3, 711-714.

Costa, F.G.P.; Brandão, P.A.; Silva, J.H.V.; Lima Neto, R.C.; Goulart, C.C.; Pereira, W.E. Exigências de cálcio para codornas japonesas fêmeas de um a 35 dias de idade. Acta Scientiarum. Animal Sciences, 2009, 31, 1, 7-12.

Costa, C.H.R.; Barreto, S.L.T.; Umigi, R.T.; Lima, H.J.D.; Araujo, M.S.; Medina, P. Balanço de cálcio e fósforo e estudo dos níveis desses minerais em dietas para codornas japonesas ( 45 a 57 semanas de idade). Revista Brasileira de Zootecnia, 2010, 39, 8, 17481755 .

Gomes, P.C.; Runho, R.C.; D’Agostini, P.; Rostagno, H.S.; Albino, L.F.T.; Lopes, P.S. Exigência de fósforo disponível para frangos de corte machos e fêmeas de 22 a 42 e de 43 a 53 dias de idade. Revista Brasileira de Zootecnia, 2004, 33, 6, 1734-1746.

Ludke, M.C.M.M; Pimentel, A.C.S; Ludke, J.V; Silva, J.C.N.S; Rabello, C.B.V; Santos, J.S. Laying performance and egg quality of japanese quails fed diets containing castor meal and enzyme complex. Revista Brasileira de Ciência Avícola, 2018, 20, 4, 781788. 
Pastore, S.; Oliveira, W.; Muniz, J. Panorama da coturnicultura no Brasil. Revista Eletrônica Nutritime, 2012, 9, 06, $2041-2049$.

Rostagno, H.S.; Albino, L.F.T.; Donzele J.L.; Gomes, P.C.; Oliveira, R.F.; Lopes, D.C.; Ferreira, A.S.; Barreto, L.S.T.; Euclides, R.F; Exigências nutricionais de codornas japonesas. In: Tabelas brasileiras para aves e suínos: composição de alimentos e exigências nutricionais, edição 3 . Universidade Federal de Viçosa: Viçosa, MG, 2011. 252p.

Sá, L.M.; Gomes, P.C.; Albino, L.F.T.; Rostagno, H.S.; D'Agostini, P. Exigências Nutricionais de cálcio e sua biodisponibilidade em alguns alimentos para frangos de corte no período de 1 a 21 dias de idade. Revista Brasileira de Zootecnia, 2004, 33, 1, 157-168.
Silva, J.; Araújo, D.M.; Lins, J.L.F.; Silva, V.M.; Tavares, A.S. Conchas de sururu mytella falcata D'orbigny, 1846 (Bivalvia: Pteriomorpha: Mytilidae) como possivel ingrediente em dietas de peixes. In: Anais do XVIII Encontro de Zoologia do Nordeste, 2013. Disponível em: http://ezn2013.blogspot.com/p/resumos.html. Acesso em: 16 Out 2018.

UFV - Universidade Federal de Viçosa. Central de Processamento de dados (UFV/CPD). Manual de utilização do Programa SAEG (Sistema para Análises Estatísticas e Genéticas). Viçosa, MG: Universidade Federal de Viçosa, 2007, 59p. 